\title{
Does risk factor epidemiology put epidemiology at risk? Peering into the future ${ }^{\star}$
}

\author{
Mervyn Susser
}

\begin{abstract}
The multiple cause black box paradigm of the current risk factor era in epidemiology is growing less serviceable. This single level paradigm is likely to be displaced. The signs are that the growing strength of molecular epidemiology on the one side, and of a global epidemiology based on information systems on the other, will come to dominate epidemiology and segregate it into separate disciplines. At the same time, the links with public health interests grow weaker. A multilevel ecoepidemiology has the potential to bind these strands together.

(F Epidemiol Community Health 1998;52:608-611)
\end{abstract}

The title of this piece is perhaps more provocative than need be. I do not renounce or repent, as fruitless, my own history of studying risk factors. My intention is to consider the future. After the second world war epidemiologists especially in the United Kingdom started out in earnest on the risk factor course, led by such as Bradford Hill and Richard Doll, Jeremy Morris, Donald Reid and Thomas McKeown. They avowed bolder aims, however, than today's risk factor epidemiologists. And soon enough they had linked lung cancer with smoking, an emblematic event.

Not chastened by the tobacco battalions' assault on causality in epidemiology - even the possibility of establishing cause - they looked for unknown and multiple causes of those chronic disorders that newly threatened the public health. Indeed, Morris named that endeavour the "search for causes". ${ }^{1}$ His own work aimed especially at the causes of coronary heart disease. Austin Bradford Hill and Richard Doll aimed at peptic ulcer, lung cancer and several other diseases besides. My generation followed in the path of that cohort of innovators.

That aetiological approach was not identical with today's risk factor epidemiology. Although it encompassed current risk factor practice, the search followed the trail wherever it led, whether at the individual, micro or macro level of organisation. One might now characterise risk factor epidemiology as the search for multiple antecedent factors at the individual level, under the guiding concept (described by the black box metaphor) that these many factors can be linked to outcomes without necessity for intervening factors. ${ }^{2}$ Legitimacy is conferred almost exclusively on analysis at the individual level.

The leading edge of the current phase is in the United States. Some might see in it a retreat from the too ambitious endeavor to establish causes, and toward a proper tentativeness. For my part, I see the phase narrowing the field of investigation, and even inducing neglect of the objective of improving the public health.

Certainly the half century search for risk factors has contributed much to public health and to clinical medicine. In epidemiology, which is our main concern, the byproducts of the search have successively clarified our understanding of research design, elucidated the problems of causal inference in a relentlessly multicausal world, and enabled us to exploit the power of computers to tackle the complexities of multiple variable analysis. In weighing all this against future necessity, a backward look might sharpen our judgment.

\section{Signal lessons from the past}

The question I want to consider first is the following: how does science, and epidemiology in particular, come to choose its concepts? To extend the question to the scientists and the future, how will they choose what they will study, and how then will they execute those studies?

The concepts we hold, I have long argued, govern the causes we seek. But concepts change. To understand how they change may help us to feel our way into the future.

From my own observations, I advance three propositions. These draw heavily on the theory of dominant paradigms and scientific revolutions, which Thomas Kuhn put forward 30 years ago. ${ }^{3}$ A Kuhnian paradigm is the overarching conceptual frame that governs the search for objective truth of most scientists in a given era. Kuhnian paradigms are finally overthrown and replaced in revolutions - in epidemiology as in other sciences.

(1) My first proposition is that paradigms are displaced not only by revolution (as in Kuhn's theory) but also by simple attrition.

A pure Kuhnian revolution occurs when new concepts of reality and/or major discoveries have overturned the common understanding. 
This was the case when finally, in the late 19th century, the revolutionary specific cause Germ Theory took hold after the work of Henle, Pasteur, Koch, and others ushered in an era of infectious disease epidemiology. Yet it is plain, in my own observation, that large changes in dominant concepts can evolve in the absence of revolutionary discovery. In most such situations, change follows because standard science is failing scientists and, in an applied discipline like ours especially, society as well. Current knowledge and procedures of a science fail in important respects to meet perceived social needs. This was the case with the advent of the early 19th century Miasma Theory and the Sanitory Movement.

Miasma was a theory of environmental context-it attributed many ills to foul nonspecific emanations. In England, urbanisation and industrialisation ensued with the enclosure of the common land. In turn, a rapidly changing profile of mortality and morbidity fundamentally changed both the nature and the perception of the health problems that faced the country. The theory had been long brewing. No new evidence-based construct or great biomedical discovery attended the adoption of the contextual cause Miasma Theory, but it fitted admirably the needs of the time for social and health reform. Important sanitary discoveries ensued. Studies of water and food pollution and occupational hazards brought significant theoretical reinforcement for miasma and considerable public health action.

This was the case also with the advent of the multiple factor, single level, black box paradigm of the era of chronic disease. In the mid20 th century, we all now know, chronic disorders increasingly displaced acute infection as the main force of mortality. The new theory that evolved in parallel to displace the specific cause Germ Theory was founded on revolution in thought. Built on the underlying idea of multiple causes for a single disorder, the theory grew out of awareness of the mystery of new epidemics of chronic disease and the necessities it imposed, much as with miasma 150 years before. In the course of time this multiple cause theory evolved into today's risk factor epidemiology.

(2) My second proposition is thus, in line with Kuhn, that major conceptual shifts, most evidently evolutionary ones but also revolutionary ones, are ultimately driven by discernible external forces.

In short, social and economic change pushes the state of knowledge in a given science up to and then beyond its limits. Awareness of the problems that need solving outruns the aptness both of concepts and of available capabilities.

(3) My third proposition is that failure of a science to invent or recognise a new paradigm, when one is needed, exacts the penalties of stagnation and inertia. Adoption of a new concept awakens a discipline to new potential.

Thus the limits of a given paradigm may bring a science to the edge of failure, and even to the outer border of oblivion. Productivity declines; young minds go elsewhere. By contrast, a new paradigm for a faltering science can be the elixir that restores it to youth.

\section{Momentum towards a new era}

The work of risk factor epidemiology with its black box paradigm may not yet be done, but the signs are ominous that we are nearing its displacement by a new era. In terms of my third proposition, we need either to adopt a new paradigm or face a sort of eclipse.

Epidemiology, a population science, is in its essence ecological in the original biological sense of organisms in a multilevel interactive environment: its subject is human ills and their prevention and control. The centre of my critique is that the study of multiple risks, confined to the individual level under the black box paradigm, does not deal with the new demands facing epidemiology. In my view, risk factor epidemiology must change or fail. The focus of the paradigm is too narrow to cope with a future that is already bearing down upon us.

On the one hand, we shall have to learn to meet the demands of newly emergent global patterns of disease. In today's world, these raise ever greater expectations of science. We are expected at the least to forestall those conditions that are, on the face of it, preventable. To do so, on the other hand, we shall have to learn to apply the relevant, radical and ever accelerating technological developments that are forging new science at the two extremes of our multilevel human world. If our discipline is to rise to meet expectations, we shall have to command both the genies of molecules at the microlevel, and of social forces at the macrolevel. Moreover, all systems, molecular or social, are dynamic. Over time, they select, adapt, and evolve. To capture the causal cycles, one must attend to time sequences at each level and across levels.

By contrast, modern risk factor epidemiology, in pure form, exploits neither the depth and precision of microlevels, nor the breadth and compass of macrolevels. It is no caricature to say that risk factor epidemiology, while properly described as a population science, none the less tends to see its objective as related to a single level of analysis and a congeries of disconnected individuals. It has little regard for the social structures and social dynamics that encompass them (a paradox that is our heritage from our ancestral origins in the individual focus of the practice of medicine).

Consider first the deficiencies of risk factor epidemiology at these higher levels of organisation. By the nature of its aims and targets, analysis has become central to the discipline. As the size of the perceptible risks we uncover grow smaller and the numbers larger, our preoccupation with analysis grows more intense. Analytic power assuredly contributes understanding. But as long as we stick to the flat surface of individual determinants and outcomes, we shall not know how to approach disease at the societal level.

New capabilities that allow us to do so are essential to dealing with true societal phenomena-virtually all diseases are that, whether infectious or not. It follows that we 
shall not fully grasp the dynamics of epidemic transmission, nor the personal behaviour and social environments that shape those dynamics. As it is, we fail with classically designed interventions against smoking; we do not block HIV and sexually transmitted diseases, nor even, in the less developed world, tuberculosis and malaria. All these and many other disorders, after all, have causes well specified at the individual level and yet defy our best efforts so far.

Now, let us turn to the microlevel. Quite recently, one can credit risk factor epidemiology with giving a hint that infection underlies Kaposi's sarcoma. ${ }^{4}$ Likewise it gave a hint that genes could underlie breast cancer. ${ }^{5}$ But these two instances are an object lesson in the advantages of multilevel study. Although the hints in each case finally led to the triumphant demonstration of virus ${ }^{6}$ and gene ${ }^{7}$ respectively, they did so because the epidemiologists involved paid close attention to the microlevel as well as the individual level.

As long as 25 years ago, indeed, card carrying epidemiologists made revolutionary discoveries at the microlevel. Yet these discoveries did not lead to a Kuhnian revolution in the guiding concepts of risk factor epidemiology. I refer first to Carleton Gajdusek's discovery of the "slow" virus (now the prion) as the proximate cause of kuru, a chronic neurological disorder of Papuans in New Guinea. ${ }^{8}$ It was not only rarely matched persistence with animal experiment at the microlevel, but close observation at the macrolevel of cultural norms and behaviour, ${ }^{9}$ that elucidated the nature of the disease. Secondly, I refer to the discovery of the hepatitis B virus (HBV) by Baruch Blumberg $^{10}$ and the subsequent work, of Alfred Prince, Wolf Szmuness, ${ }^{11}$ and Palmer Beasley, ${ }^{12}$ that established HBV as a proximate cause of liver cancer, another chronic disease. Here we saw the standard methods of epidemiology applied to ostensibly non-infectious disease without neglecting either micro or macrolevels and, in the process, eliciting unknown and unanticipated infectious causes.

Despite these revolutionary discoveries, on one side many infectious disease epidemiologists continued to ignore mainstream epidemiology methods. On another side, few mainstream chronic disease epidemiologists took up the challenge of the microlevel. As for the macrolevel, little but derision has met ecological approaches. Worthwhile and successful effort has gone into elucidating their weaknesses and difficulties. Very little positive effort has yet gone into overcoming those undeniable difficulties. ${ }^{13}$ The dominant risk factor black box obscures our vision and impedes our capacity to deal with the near future.

\section{What lies ahead?}

Two strong currents, I have intimated, are already penetrating the domain of epidemiology and carrying it beyond the confines of risk factor epidemiology. On the microlevel, molecular biology has led to the staking of strong claims for a molecular epidemiology. On the macrolevel, the development of communica- tion systems, information networks, and modelling techniques has led to the possibility of a dynamic global epidemiology. Each has the potential power of a new subdiscipline. Acting simultaneously, but independently, they could quite soon overwhelm a parent discipline that retains its conventional form of single level analysis. These portents are given force by history.

To turn first to the microlevel, the scientific revolution that entrenched the Germ Theory can serve as a historical counterpart for molecular epidemiology. The specific cause model it spawned had enormous scientific attraction in its directness and illusory simplicity. A succession of spectacular microbiological discoveries conferred eponymous fame on one bacteriologist after another. As the Miasma Theory faded, the momentum of environmentally oriented epidemiology was lost. Aspiring scientists who sought to satisfy altruistic or social goals looked elsewhere. In the antecedent period of Sanitary Statistics epidemiologists (not always labelled as such) had been many and distinguished. ${ }^{14}$ Now they shrank, possibly in numbers but clearly in distinction. ${ }^{2}$ Rather than being the creative scientific pace setters of public health, they served largely in the role of handmaidens, applying the work of their bacteriological colleagues. It was not ignominious, but it was secondary in the advance of public health science.

When we turn to the macrolevel, epidemiology can trace a history from the observations on Air, Water and Places of the Hippocratic School on the Island of Cos in the 4th century BC, through the modelling and other contextual analyses of William Farr in the early 19th century era of Sanitary Statistics, and on to a small but steady stream of modellers who, in the early 20 th century, focused mainly on epidemic phenomena but sometimes also on broader context. Among them one may count J Brownlee, W H Hamer, Ronald Ross, Major Greenwood, and others. ${ }^{15}$

The ecological level of analysis is alive and well in terms of the modelling of the dynamics both of epidemic transmission and of social process. With rather few exceptions, however, it is little practiced by trained epidemiologists. Yet it makes major contributions in other disciplines, as in econometrics, climatology, and the study of global warming. Hence this territory too is very likely, under our prevailing black box paradigm, to be ceded to other disciplines.

\section{What should we do now? And can we do it?}

Ezra Susser and I have advocated ecoepidemiology as a choice for a possible future ${ }^{2}$ that we believe is virtually upon us now. For the paradigm of such a new era we offered the metaphor of Chinese boxes. The essence of this paradigm is that it integrates multiple levels of a designated problem, either in sequence as the needed data are acquired, or simultaneously if the resources to acquire and analyse those data are in hand. In either event, the epidemiologist's need to hypothesis, design, and analysis would always keep in focus the object of view- 
ing all the relevant levels as a whole. Each level is seen as a system in itself that interacts with those above and below it. This is not to say that epidemiology would relax its historic focus on populations, but that epidemiologists would need to absorb and apply the advancing scientific understanding at other levels to the study in breadth and depth of the human population level.

Such an approach, it can reasonably be objected, demands technical capabilities and analytic tools beyond the present day resources of epidemiology. I resort to two points in rebuttal. My resort is again to history, first that of science in general, and second that of research practice in epidemiology in particular.

The development of science in general is replete with examples of problems posed and tackled before suitable tools were in hand. In epidemiology within my own lifetime, for example, the methods for design, analysis, and inference under the multiple cause idea that gave rise to the black box paradigm and (eventually) to the risk factor mode were at the outset far from matching the needs of the researchers. ${ }^{16}$ Quite clearly, the antecedent attempts to apply the concept and to meet its critics generated the methodological development that followed. The search for multiple causes haltingly established the case-control and cohort designs and the many analytic advances that followed.

My second resort, to the particular history of research in epidemiology, shows that an ecoepidemiology is viable and can be productive. More and less successful examples of multilevel ecoepidemiological research can be found in the work of several major figures in epidemiology. One can begin with William Farr and John Snow, at times in collaboration. Farr used the Miasma model, and invented a methodology to cope with it. But he did not confine himself to any one level. Thus he was quickly accepting of Henle's 1840 formulation of the Germ Theory. In the cholera epidemics of the mid-19th century, he contributed the data for Snow's "grand experiment."17

Snow's work moves freely and fascinatingly across different levels: he compared water supply and cholera mortality ecologically by district in 1849 versus 1854, helped to conduct the Reverend Whitehead's proto-case-control study of cholera cases and use of the Broad Street Pump ${ }^{\star}$, analysed the natural experiment of cholera deaths in households stratified by Lambeth versus Southwark and Vauxhall water supply, noted the individual case of Mrs Eley who, uniquely in Hampstead, fell victim because she used water from the Broad Street Pump. Finally, at the microscopic level, he correctly speculated that some sort of microorganisms in Thames water were involved. ${ }^{18}$

Ronald Ross won the Nobel Prize in 1902 for his work on malaria at the microlevel, and then moved on to the ecological level of epidemic transmission in his pursuit of

${ }^{\star}$ I owe this insight about design to Nigel Paneth. prevention by the elimination of anopheline mosquitoes. ${ }^{19}$

In the same period, Joseph Goldberger began his pursuit of the causes of pellagra. ${ }^{20}$ In the US, the disorder was then commonly held to be infectious. In a succession of studies, observational and experimental, individual and ecological, Goldberger traced the condition in the Southern states to malnutrition and the enforced poverty of agricultural workers.

Later in this century, too, one can find several distinguished examples (A few among the several reside in the work of Thomas Francis, Ancel Keys, Richard Doll, Thomas Mckeown, Jeremy Morris, Milton Terris, Jeremiah Stamler, George Comstock, John Cassel, and Warren Winklestein).

With this quite illustrious list, I rest my case: I am proposing a paradigm that we have seen slowly evolving; I have shown that the work of some of our greatest predecessors illustrates this paradigm; and I predict that the methods needed for fully exploiting such a paradigm will surely follow. The United Kingdom pioneered multiple cause epidemiology. The necessity of a new paradigm I believe, once more lies before us. I am not a millennarian, but the right choice may just save the discipline of epidemiology as we know it from limbo.

1 Morris JN. Uses of epidemiology. Edinburgh: Livingstone, 1957

2 Susser M, Susser E. Choosing a future for epidemiology: I. Eras and paradigms. 11. From black boxes to Chinese boxes. Am $\mathcal{F}$ Publ Health 1996;86:668-73;674-8.

3 Kuhn TS. The structure of scientific revolutions. 2nd ed. Chicago: University of Chicago Press, 1970.

4 Beral V. Risk of Kaposi's sarcoma in persons with AIDS: A sexually transmitted infection? Lancet 1990;335:123-8.

5 Ottman R, Pike MC, King MC, et al. Practical guide for estimating risk for familial breasts cancer. Lancet 1983;ii: $556-8$.

6 Chang Y, Cesarman E, Pessin MS, et al. Identification of herpesvirus-like DNA sequence in AlDS-associated Kaposi's sarcoma. Science 1994;266:1865-9.

7 Hall JM, Lee MK, Newman B, et al. Linkage of early onset Hall JM, Lee MK, Newman B, et al. Linkage of early onset
familial breast cancer to chromosome 17Q21. Science

8 Gajdusek DC, Zigas V. Degenerative disease of the central nervous system in New Guinea. $N$ Engl F Med 1957;257: 974-8.

9 Lindenbaum S Kuru. Sorcery: disease and danger in the New Guinea Highlands. Palo Alto, CA: Stanford University Press, 1973 .

10 Blumberg BS. Adaption to infectious disease. Australia antigen and hepatitis. Am f Phys Anthropol 1970;32:305-8.

11 Prince AM, Szmuness W, Michon J, et al. A case-control study of the association between primary liver cancer and A 83 .

12 Beasley RP, Hwang LY, Cin CC, et al. Hepatocellular carcinoma and hepatitis B virus. A prospective study of 22,707 men in Taiwan. Lancet 1981;ii:1129-33.

13 Susser M. The logic in ecological. Part I, The logic of analysis. Part II, The logic of design. Am F Publ Health 1994;84: 825-35

14 Brockington CF. Public health in the 19th century. Edinburgh: E and S Livingstone, 1965

15 Susser M. Causal thinking in the health sciences. Oxford: Oxford University Press, 1973;32-40..

16 Susser M. Epidemiology in the United States after world war II: The evolution of technique. Epidemiol Rev $1985 ; 7: 147-77$

17 Susser M, Adelstein A. The work of William Farr. Reprinted from "An Introduction" vital statistics: A memorial volume selections from the reports and writings of William Farr, 1885 (NN Humphreys, ed). In: Susser M. Epidemiology, health and society. New York: Oxford University Press,

18 Snow J. On the mode-of communication of cholera. 2nd ed. London: J Churchill, 1855. Reprinted as Snow on cholera. New York: Commonwealth Fund, 1936

19 Ross Sir R. The prevention of malaria. 2nd ed. New York: EP Dutton, 1910.

20 Terris M. Goldberger on pellegra. Baton Rouge: Lousiana State University Press, 1964. 